\title{
APLIKASI UNTUK MENGUKUR BAJU DENGAN SENSOR ULTRASONIK
}

\author{
Kevin Kurniawan ${ }^{1}$, Sutrisno $^{2}$, Pujianto Yugopuspito ${ }^{3}$ \\ 1),2),3) Teknik Informatika, Universitas Pelita Harapan \\ Lippo Karawaci, Tangerang \\ yugopuspito@uph.edu
}

\begin{abstract}
ABSTRAK
Beberapa toko pakaian melarang pengunjung mencoba mengenakan baju yang akan dibelinya, terutama baju berjenis ketat dan berwarna terang. Penelitian ini mengusulkan sistem yang dapat membantu pengunjung toko pakaian untuk mengetahui ukuran baju yang sesuai tanpa harus mencoba mengenakannya. Aplikasi Android dibuat untuk menampilkan hasil penentuan ukuran baju dengan bantuan alat pengukur, yaitu sensor ultrasonik HC-SR04 dengan mikrokontroler Arduino. Aplikasi ini digunakan sebagai media interaksi antara pengguna dengan alat pengukur agar lebih mudah dalam menggunakannya. Alat pengukur digunakan untuk mendapatkan ukuran bagian tubuh pengguna. Pengukuran dilakukan menggunakan teknik perhitungan jarak ultrasonik yang hasilnya dikalkulasi untuk mendapatkan ukuran bagian tubuh. Penentuan bagian tubuh dilakukan berdasarkan data antropometri Indonesia. Dari hasil uji coba pengukuran, didapatkan keberhasilan untuk mendapatkan ukuran baju sebesar $100 \%$ dengan kebenaran hasil ukuran sebesar $82.0 \%$
\end{abstract}

Keyword : pengukuran, penentuan, baju, aplikasi, ultrasonik.

\section{PENDAHULUAN}

Ketika pengunjung hendak membeli pakaian, beberapa toko pakaian melarang pengunjung untuk mencoba baju yang akan dibelinya, terutama untuk yang berjenis ketat atau yang berwarna terang. Di sementara, calon pembeli mengharapkan baju yang akan dibeli sesuai dengan ukuran tubuhnya dan larangan ini dapat membuat calon pembeli kesulitan untuk menentukan ukuran yang tepat. Maka, diperlukan adanya sistem yang dapat membantu calon pembeli untuk mengetahui ukuran baju apa yang sesuai dengan ukuran tubuhnya dengan tepat, tanpa harus mencoba mengenakannya

Permasalahan yang akan dipecahkan dalam penelitian ini adalah bagaimana merancang sebuah sistem agar dapat mengetahui ukuran baju yang hendak dibeli di toko pakaian tanpa harus mengenakannya, sistem dapat menetapkan ukuran baju yang tepat, dan sistem dapat mengolah hasil pengukuran tubuh menjadi ukuran baju yang sesuai. Pengukuran bagian tubuh memanfaatkan sensor ultrasonik HC-SR04 yang dihubungkan dengan mikrokontroler Arduino untuk mengelolanya. Ketika pengukuran selesai dilakukan, maka ukuran baju akan ditetapkan dan ditampilkan secara realtime melalui aplikasi yang dibangun untuk telepon cerdas berbasis Android

Penelitian ini meliputi empat tahapan yang dilakukan secara terstruktur dan sistematis, yaitu studi literatur, perancangan sistem, implementasi sistem, serta analisa dan uji coba sistem. Tahapan ini disusun untuk mendapatkan hasil yang optimal dan mampu menyelesaikan masalah dengan tepat.

Beberapa dasar teori yang digunakan adalah:

Pengukuran Baju - Antropometri merupakan ilmu yang mempelajari tentang bentuk atau ukuran tubuh manusia yang berkaitan dengan pengukuran dimensi tubuhnya. Data antropometri dapat digunakan untuk perancangan barang agar memperoleh ukuran yang sesuai dengan dimensi tubuh manusia yang akan menggunakannya. Antropometri juga dapat digunakan dalam perancangan busana, salah satunya untuk pengukuran baju yang disesuaikan dengan dimensi tubuh manusia. [1]

Efek Doppler adalah perubahan frekuensi atau panjang gelombang yang diterima oleh pengamat jika sumber suara atau gelombang bergerak relatif terhadap pengamat atau pendengar. Ketika sumber bunyi bergerak mendekati pengamat, maka ketinggian nada akan lebih tinggi daripada ketika sumber bunyi diam. Sebaliknya, ketika sumber bunyi menjauhi pengamat, maka ketinggian nada akan menjadi lebih rendah. Selain itu, efek Doppler juga terjadi ketika pengamat bergerak dan sumber bunyi diam. Jika pengamat menjauhi sumber, ketinggian nada akan lebih rendah dan jika pengamat mendekati sumber, ketinggian nada akan lebih tinggi. [2]

Teknik pengukuran jarak menggunakan ultrasonik memanfaatkan pemantulan dari gelombang suara ultrasonik yang tidak terdengar oleh manusia. Medium yang digunakan adalah udara sehingga tidak dibutuhkan kontak langsung. Subyek yang memiliki dimensi lebih besar dari panjang gelombang suara yang mengenainya akan memantulkan gelombang suara tersebut, dimana gelombang yang dipantulkan disebut echo. [3] Teknik ini menggunakan ultrasonik di udara yang meliputi metode getaran echo yang berkelanjutan, rentetan getaran dikirimkan untuk transmisi medium dan dipantulkan oleh subyek pada jarak yang spesifik. [4] Jika kecepatan suara pada medium diketahui dan waktu yang dibutuhkan untuk sumber dari saat mengeluarkan gelombang suara hingga menerima kembali pantulannya diketahui, maka 
jarak dari sumber ke subyek dapat diukur secara akurat. [3]

Rumus perhitungan jarak menggunakan ultrasonik [5] adalah

$\mathrm{d}=\mathrm{k} \times \mathrm{V} \times \mathrm{t}$

dimana d menyatakan jarak (m), k menyatakan faktor koreksi, t menyatakan waktu (s). Sementara V menyatakan kecepatan suara $(\mathrm{m} / \mathrm{s})$ dengan koreksi suhu, $\mathrm{T}\left({ }^{\circ} \mathrm{C}\right)$, yaitu

$\mathrm{V}=340+0.6(\mathrm{~T}-15)$

Outlier adalah nilai data yang sangat besar atau sangat kecil jika dibandingkan dengan nilai data lainnya. Outlier sangat mempengaruhi nilai ratarata, standar deviasi dari suatu variabel, serta dapat mempengaruhi nilai statistik lainnya. Untuk mengecek outlier pada sekumpulan data, gunakan langkah berikut. [6]

1) Urutkan data dan cari kuartil ke-1 (Q1) dan kuartil ke-3 (Q3) dari data tersebut.

2) Cari interquartile range (IQR) menggunakan persamaan IQR = Q3-Q1.
3) Kalikan IQR dengan 1.5.

4) Kurangi nilai yang didapat pada langkah 3 dari Q1 dan tambahkan nilai tersebut pada Q3.

Cek pada kumpulan data untuk data yang bernilai kurang dari Q1 - 1.5(IQR) atau yang lebih dari Q3 - 1.5(IQR).

\section{PEMBAHASAN}

Ada tiga hal yang akan dibahas dalam penelitian ini: Perancanang Sistem, Implementasi dan Pemaparan Hasil.

\subsection{Perancangan Sistem}

Alat ukur yang dibuat terdiri dari dua puluh sensor ultrasonik HC-SR04. Sensor ini dihubungkan dengan mikrokontroler Arduino Mega 2560 yang akan mengelola sensor tersebut dan mendapatkan hasil pengukuran dari lebar dan ketebalan bagian tubuh. Tiang dirancang khusus untuk menempatkan sensor, dimana sepuluh sensor diletakkan di bagian kiri dan sepuluh sensor lainnya diletakkan di bagian kanan secara sejajar. Pengukuran dimulai dari sensor urutan teratas agar ketika sensor berhasil mengenali dan mengukur bagian tubuh yang ditentukan, maka sensor pada urutan selanjutnya tidak perlu melakukan pengukuran. Rancangan alat pengukur dapat dilihat pada Gambar 1.

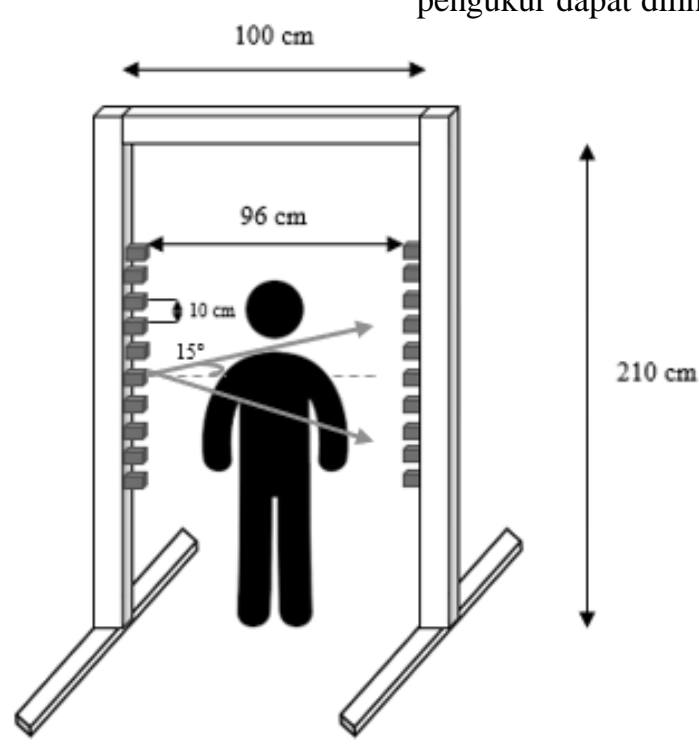

Gambar 1. Rancangan Alat Pengukur

Alat pengukur akan mulai melakukan pengukuran ketika aplikasi Android memberikan pemicu (trigger) kepada mikrokontroler dengan mengirimkan suatu data yang akan disesuaikan pada kedua perangkat. Selanjutnya, setelah pengukuran berhasil dilakukan, data hasil pengukuran yang didapat akan diterima oleh mikrokontroler yang digunakan dan akan dikirim ke aplikasi Android melalui komunikasi serial antar kedua perangkat. Komunikasi serial ini dilakukan dengan menghubungkan kedua perangkat tersebut menggunakan kabel USB 2.0 Tipe A/B yang disambung dengan kabel USB OTG. Mekanisme pengiriman data dapat dilihat pada Gambar 2. 


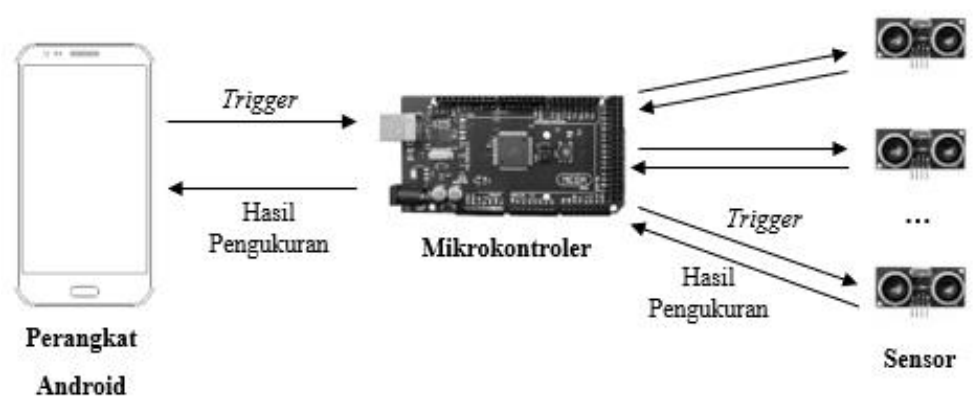

Gambar 2. Mekanisme Pengiriman Data

Aplikasi dibangun pada telepon cerdas berbasis Android dengan menggunakan bahasa pemrograman Java pada Android Studio. Dalam aplikasi ini, terdapat pengimplementasian fitur USB host sehingga memungkinkan aplikasi dapat berkomunikasi dengan perangkat lain yang dihubungkan melalui kabel USB. Pangkalan data yang digunakan adalah SQLite, dengan bahasa SQL untuk menyimpan riwayat pengukuran yang dilakukan melalui aplikasi. Use Case Diagram dari aplikasi yang dibuat dapat dilihat pada Gambar 3 .

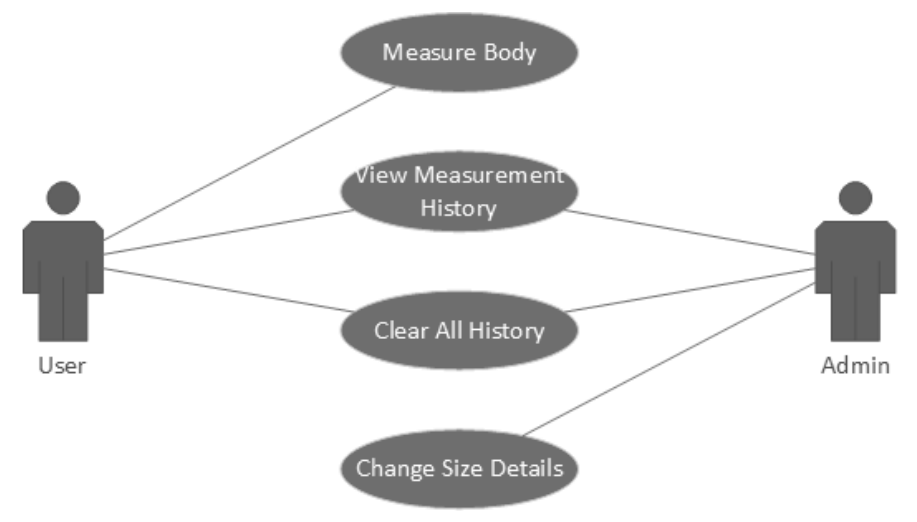

Gambar 3. Use Case Diagram

\subsection{Implementasi Sistem}

Alat pengukur diimplementasikan pada mikrokontroler Arduino menggunakan bahasa pemrograman $\mathrm{C}$ dengan Arduino IDE. Rangkaian Arduino dengan sensor HC-SR04 dapat dilihat pada Gambar 4

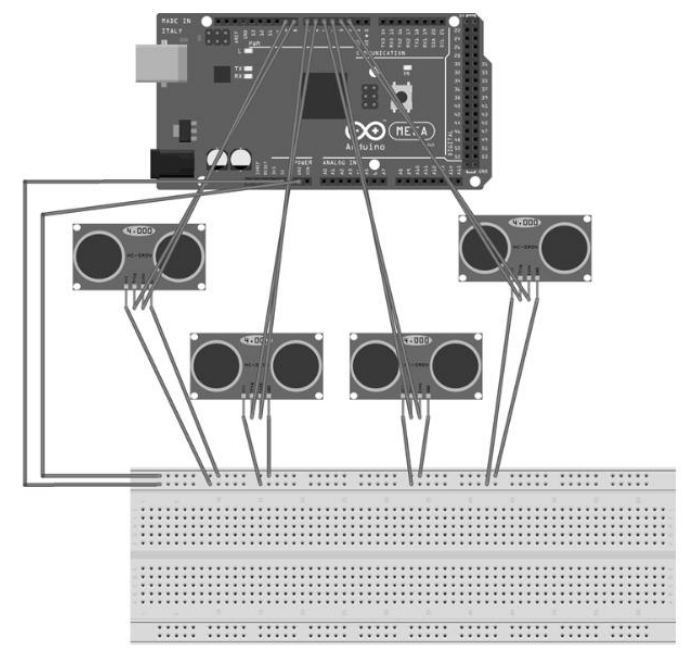

Gambar 4. Rangkaian Arduino dengan sensor HC-SR04 
Pengukuran dengan menggunakan dua puluh sensor HC-SR04 dilakukan secara bergantian per baris menggunakan looping, mulai dari sensor dengan urutan teratas hingga urutan terbawah.
Mekanisme pengukuran dibagi menjadi dua macam, yaitu pengukuran lebar bahu, serta pengukuran lebar atau tebal bagian dada dan pinggang. Alat pengukur dapat dilihat pada Gambar 5.

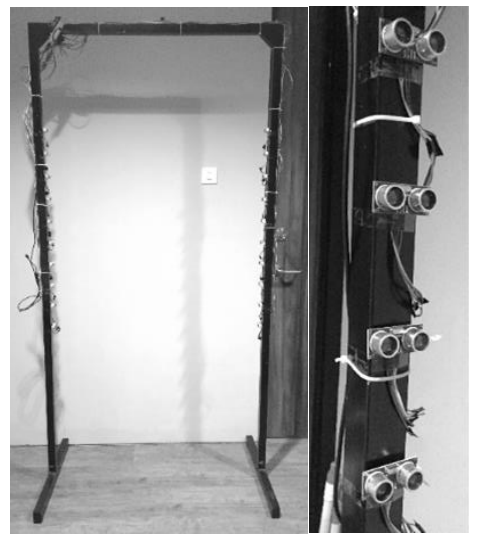

Gambar 5. Alat Pengukur

Obyek yang diukur adalah bagian tubuh manusia, maka permukaan yang diukur tidak rata, dan cenderung menyebabkan sudut yang terbentuk antara gelombang yang dikirim dan dipantulkan melebihi sudut yang dapat ditoleransi oleh sensor. Maka, akan dilakukan pengecekan apakah sistem berhasil mendapatkan ukuran setelah pengukuran dilakukan. Jika belum berhasil, maka pengukuran akan diulang.

Penentuan indeks sensor yang mengukur bagian tubuh tertentu dikenali dan ditetapkan berdasarkan data antropometri Indonesia yang digunakan. Untuk setiap metode pengukuran, akan dilakukan pengukuran sebanyak lima kali iterasi untuk meningkatkan kebenaran hasil yang didapat. Hasil dari setiap iterasi disimpan sementara dan dilakukan eliminasi terhadap hasil yang termasuk nilai outlier.
Selanjutnya, pengiriman data diimplementasikan menggunakan komunikasi serial antara Arduino dan aplikasi Android. Data yang dikirimkan melalui komunikasi serial ini bertipe data byte. Pengiriman data dilakukan secara dua arah, yaitu dari aplikasi Android ke Arduino dan dari Arduino ke aplikasi Android. Untuk dapat melakukan komunikasi serial, maka pada aplikasi Android ditambahkan dependency terhadap suatu library yang membantu dalam menghubungkan aplikasi Android dengan Arduino serta mengatur pertukaran data di antaranya.

Kemudian, aplikasi diimplementasikan untuk dijalankan pada platform Android menggunakan bahasa pemrograman Java dengan Android Studio IDE. Tampilan dari aplikasi dapat dilihat pada Gambar 6
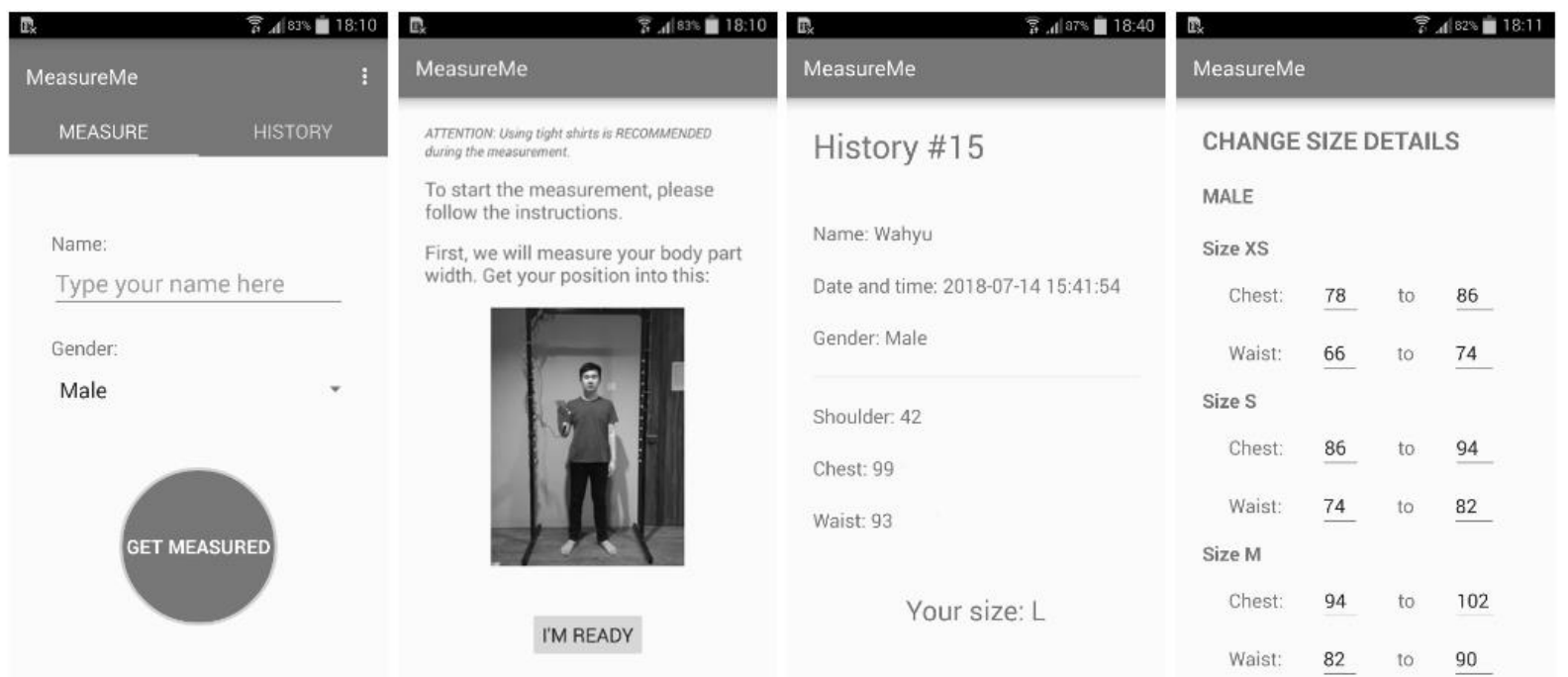

Gambar 6. Tampilan Aplikasi 


\subsection{Paparan Hasil}

Pengujian akan dilakukan dengan melakukan percobaan pada semua fungsi aplikasi yang telah diimplementasikan dan melakukan uji coba pengukuran pada sepuluh orang yang berbeda (jenis kelamin dan ukuran tubuhnya) sebanyak lima kali untuk setiap orangnya. Hasil pengukuran berupa ukuran lebar bahu, ukuran lingkar dada, ukuran lingkar pinggang, dan ukuran baju yang sesuai. Hasil yang didapat dianalisa setelahnya

Hasil dari pengujian aplikasi menyatakan bahwa keseluruhan fungsi aplikasi berhasil diimplementasikan sesuai dengan rancangan. Dari hasil pengukuran lebar bahu, terdapat keberagaman hasil pengukuran maksimal sebesar $5.0 \%$ berdasarkan persentase nilai standar deviasi dengan nilai rata-ratanya. Selisih maksimal dari hasil pengukuran lebar bahu dengan ukuran sebenarnya mencapai $5 \mathrm{~cm}$. Ukuran lebar bahu hanya digunakan untuk menentukan indeks sensor yang mengukur bagian dada dan pinggang, serta tidak digunakan dalam menentukan ukuran baju sehingga selisih dari hasil pengujian dapat diterima.

Dari hasil pengukuran lingkar dada, terdapat keberagaman hasil pengukuran maksimal sebesar $6.1 \%$ berdasarkan persentase nilai standar deviasi dengan nilai rata-ratanya. Ukuran lingkar dada digunakan dalam menentukan ukuran baju. Rentang ukuran lingkar dada untuk suatu ukuran baju yang digunakan dalam pengujian ini adalah $9 \mathrm{~cm}$ sehingga $100 \%$ selisih maksimal dari hasil pengukuran lingkar dada dengan ukuran sebenarnya dapat diterima.

Dari hasil pengukuran lingkar pinggang, terdapat keberagaman hasil pengukuran maksimal sebesar $8.7 \%$ berdasarkan persentase nilai standar deviasi dengan nilai rata-ratanya. Ukuran lingkar pinggang digunakan dalam menentukan ukuran baju. Rentang ukuran lingkar pinggang untuk suatu ukuran baju yang digunakan dalam pengujian ini adalah $9 \mathrm{~cm}$ sehingga $60.0 \%$ selisih maksimal dari hasil pengukuran lingkar pinggang dengan ukuran sebenarnya dapat diterima.

Tabel 1 adalah hasil pengujian dari 10 data, tampak bahwa $100 \%$ ukuran baju berhasil didapatkan dari keseluruhan pengujian. Semua ukuran baju berhasil karena semua memiliki ukuran tubuh yang termasuk dalam rentang ukuran data antropometri yang digunakan. Berdasarkan ukuran baju yang berhasil ditentukan yang dibandingkan dengan ukuran baju sebenarnya, maka persentase kebenaran dari hasil penentuan ukuran baju menggunakan sistem adalah sebesar $82.0 \%$. Faktorfaktor seperti pakaian yang digunakan dan posisi saat melakukan pengukuran mempengaruhi kebenaran penentuan ukuran baju.

\section{KESIMPULAN}

Berdasarkan hasil pengujian terhadap sistem yang telah dibuat dan analisa terhadap hasil pengukuran, maka dapat disimpulkan bahwa sistem berhasil melakukan pengukuran bagian tubuh dan menentukan ukuran baju pengguna. Hasil uji coba pengukuran menunjukkan bahwa persentase keberhasilan penentuan ukuran baju oleh sistem sebesar $100 \%$ dengan persentase kebenarannya sebesar $82.0 \%$. Sensor ultrasonik HC-SR04 yang dihubungkan dengan mikrokontroler Arduino berhasil digunakan untuk melakukan pengukuran bagian tubuh. Aplikasi Android yang dibuat juga mampu menetapkan ukuran baju dan menampilkan hasil pengukuran secara real-time.

Tabel 1. Persentase kebenaran dari penentuan ukuran baju.

\begin{tabular}{|c|c|c|c|c|c|c|c|c|}
\hline \multirow[t]{2}{*}{ Penguji } & \multirow{2}{*}{$\begin{array}{l}\text { Jenis } \\
\text { Kelamin }\end{array}$} & \multirow{2}{*}{$\begin{array}{c}\text { Ukuran } \\
\text { Sebenarnya }\end{array}$} & \multicolumn{5}{|c|}{$\begin{array}{c}\text { Ukuran yang Didapat } \\
\text { Pengujian }\end{array}$} & \multirow{2}{*}{$\begin{array}{l}\text { Persentase } \\
\text { Benar }(\%)\end{array}$} \\
\hline & & & 1 & 2 & 3 & 4 & 5 & \\
\hline Penguji 1 & Wanita & M & $\mathrm{M}$ & M & $\mathrm{M}$ & $\mathrm{L}$ & $\mathrm{L}$ & 60 \\
\hline Penguji 2 & Pria & $\mathrm{L}$ & $\mathrm{L}$ & $\mathrm{M}$ & $\mathrm{L}$ & $\mathrm{L}$ & $\mathrm{L}$ & 80 \\
\hline Penguji 3 & Pria & $\mathrm{M}$ & $\mathrm{M}$ & $\mathrm{M}$ & $\mathrm{M}$ & $\mathrm{M}$ & $\mathrm{M}$ & 100 \\
\hline Penguji 4 & Pria & M & M & M & M & M & M & 100 \\
\hline Penguji 5 & Wanita & $\mathrm{L}$ & $\mathrm{L}$ & $\mathrm{L}$ & $\mathrm{L}$ & $\mathrm{L}$ & $\mathrm{L}$ & 100 \\
\hline Penguji 6 & Pria & $\mathrm{L}$ & $\mathrm{L}$ & $\mathrm{L}$ & $\mathrm{XL}$ & $\mathrm{L}$ & $\mathrm{L}$ & 80 \\
\hline Penguji 7 & Wanita & $\mathrm{S}$ & $\mathrm{S}$ & $S$ & $\mathrm{M}$ & $\mathrm{M}$ & $S$ & 60 \\
\hline Penguji 8 & Wanita & $\mathrm{XS}$ & $\mathrm{S}$ & $\mathrm{S}$ & $\mathrm{XS}$ & $\mathrm{XS}$ & $\mathrm{XS}$ & 60 \\
\hline Penguji 9 & Pria & $\mathrm{XL}$ & $\mathrm{XL}$ & $\mathrm{XL}$ & $\mathrm{XL}$ & $\mathrm{XL}$ & $\mathrm{XL}$ & 100 \\
\hline Penguji 10 & Wanita & $S$ & $S$ & $\mathrm{~S}$ & $\mathrm{~S}$ & S & XS & 80 \\
\hline \multicolumn{8}{|c|}{ Persentase benar dari keseluruhan pengujian } & $82.0 \%$ \\
\hline
\end{tabular}


Saran pengembangan yang dapat dilakukan adalah sebagai berikut.

1) Penggunaan motor servo sebagai lintasan sensor pada tiang sehingga sensor yang digunakan dapat bergerak secara dinamis.

2) Eksperimen peletakan sensor pada posisi yang berbeda untuk membandingkan hasil pengukuran yang diperoleh.

3) Penghubungan aplikasi Android dengan Arduino dan pengiriman data dapat dijadikan wireless.

4) Pengembangan sistem untuk dapat menentukan ukuran pakaian jenis lainnya, selain baju.

5) Meningkatkan sistem agar juga mendukung pengguna yang memiliki ukuran tubuh di luar ukuran data antropometri yang digunakan dan penambahan ukuran perut untuk antisipasi orang berperut buncit atau gendut.

\section{DAFTAR PUSTAKA}

[1]. Supriyanto, Firman dan Arief Rahman. Perancangan Sistem Pengukuran Antropometri Badan and Pembuatan Pola dalam Industri Konveksi dengan Menggunakan Image Processing. Jurnal Institut Teknologi Sepuluh Nopember. 2017; 3.
[2]. Habibi, Najibuddin dan Imam Sucahyo. Perancangan Alat Ukur Kecepatan Menggunakan Sensor Ultrasonik dan Prinsip Efek Doppler. Jurnal Inovasi Fisika Indonesia. 2015; 4(3): 48-54

[3]. Anju Latha, Rama Murthy, and K Bharat Kumar. Distance Sensing with Ultrasonic Sensor and Arduino. International Journal of Advance Research, Ideas and Innovations in Technology 2 No. 5 (2016): 1-5

[4]. Soni, Neeraja, Shrikant Maheshwari, Basant Kumar Sahu, Bhavishya Jain, and Garima Shrivastava. Distance Measurement Using Ultrasonic Sensor and Arduino. International Journal of Engineering Science and Computing. 2017; 7(3): 1-2.

[5]. Thomas, Rajan P, Jithin K K, Hareesh K S, Habeeburahman C A, and Jithin Abraham. Range Detection Based on Ultrasonic Principle. International Journal of Advanced Research in Electrical. 2014; 3(2): 7638-7642

[6]. Bluman, Allan G. Elementary Statistics. A Step by Step Approach. 8th edition. New York: McCgraw-Hill. 1998: 151. 